\title{
Brown-Séquard syndrome from herniation of a thoracic disc
}

\author{
Christopher D. Witiw MD, Mohammed F. Shamji MD PhD
}

$\mathrm{A}$ healthy 36-year-old man presented to the emergency department with a painless and progressive left footdrop, numbness in the right leg and urinary hesitancy for 10 days. Physical examination showed the following signs affecting the patient's left side: weakness in all myotomes of the lower extremity (most prominent in the distal muscle groups), abnormal proprioception of the toes, brisk reflexes and an upgoing plantar reflex. Sensation to sharp touch and temperature was diminished in the dermatomes on the right side caudal to T10. The clinical pattern indicated incomplete hemisection of the spinal cord, classically associated with Charles Edouard Brown-Séquard, who first described the now eponymous syndrome in the mid-19th century. ${ }^{1}$

Magnetic resonance imaging (MRI) showed herniation of the intervertebral disc between $\mathrm{T} 8$ and $\mathrm{T}$, suspected to be intradural, with hemi-spinal cord compression on the left side (Figures 1A and 1B). Computed tomography showed calcification of the herniated disc (Figure 1C).

In Brown-Séquard syndrome, the contralateral loss of sensation to sharp touch and temperature is attributable to the compression of the neurons in the spinothalamic tract, decussating near where they enter the spinal cord. Disruption of this ascending tract leads to sensory loss opposite to the compression. The ipsilateral weakness and loss of proprioception result from compression of the lateral corticospinal tract and posterior columns, respectively. These neurons decussate in the brainstem medulla; therefore, functional loss is ipsilateral to the lesion (Figure 1D). These hallmark findings are associated with penetrating injuries to the spinal cord, compressive extramedullary spinal tumours, hematomas, herniated intervertebral discs and numerous other causes., ${ }^{2,3}$ Prompt surgical intervention is often required; therefore, expedited MRI of the spine should be performed for any patient presenting with Brown-Séquard syndrome.

This patient, without predisposing conditions for disc herniation, underwent urgent posterior surgical decompression and resection of the intradural disc, which required division of
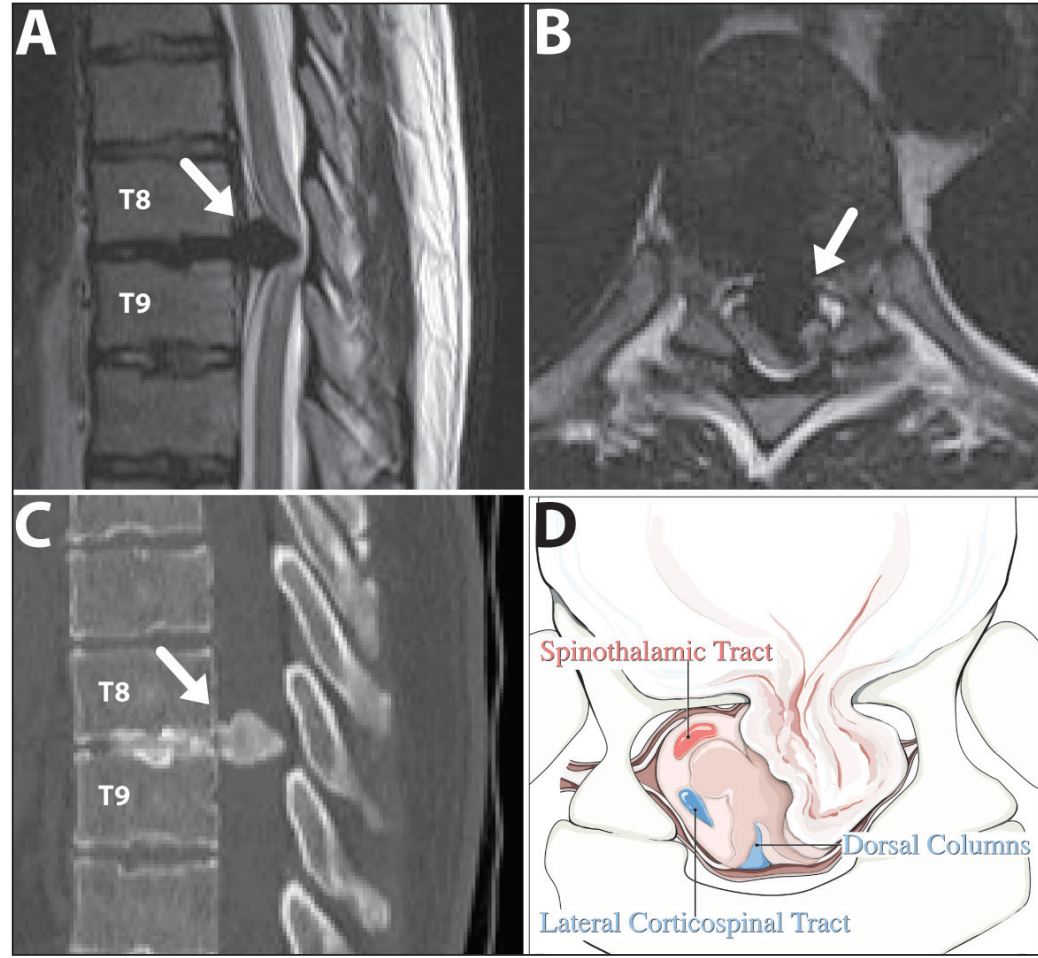

Figure 1: Magnetic resonance imaging scans ( $T_{2}$-weighted) of the spine in (A) sagittal and (B) axial view, showing a large, herniated intervertebral disc between T8 and T9 (white arrow) with spinal cord compression. (C) Computed tomography scan in sagittal view, showing calcification of the herniated disc (white arrow). (D) Illustration of an axial view of the spine between T8 and T9, showing the compressive effects of the disc herniation on the sensory and motor pathways of the spinal cord on the left side.

the T9 nerve root on the left side, and instrumented fusion. Postoperatively, the patient regained ambulatory function and only experiences the expected left-sided sensory deficit at the T9 level.

\section{References}

1. Brown-Séquard CE. Lectures on the physiology and pathology of the nervous system and on the treatment of organic nervous affections: lecture II, part 1. Lancet 1869;93:1-3.

2. Koehler PJ, Endtz LJ. The Brown-Séquard syndrome. True or false? Arch Neurol 1986;43:921-4.

3. Diabira S, Henaux PL, Riffaud L, et al. Brown-Séquard syndrome revealing intradural thoracic disc herniation. Eur Spine J 2011; 20:65-70.

Affiliations: Division of Neurosurgery, Department of Surgery (Witiw, Shamji), University of Toronto, Toronto, Ont.; Division of Neurosurgery (Shamji), Toronto Western Hospital, Toronto, Ont.
Competing interests: None declared.

This article has been peer reviewed.

The authors have obtained patient consent.

Correspondence to: Mohammed Shamji, mohammed.shamji@uhn.ca

Acknowledgement: The authors thank Marissa Webber for providing the illustration in Figure 1D.

CMAJ 2014. DOI:10.1503 /cmaj.140117 